\title{
Comparison of ozonation and coagulation decolorization methods in real textile wastewater
}

\author{
M.I. Aydin, B. Yuzera, A. Ongenn, H.E. Okten ${ }^{\mathrm{b}}$, H. Selcuk ${ }^{\mathrm{a}, *}$ \\ astanbul University, Faculty of Engineering, Department of Environmental Engineering, Avcilar, Istanbul, Turkey, \\ email:iberia@istanbul.edu.tr(M.I. Aydin),byuzer@istanbul.edu.tr(B.Yuzer),aongen@istanbul.edu.tr (A.Ongen), \\ hselcuk@istanbul.edu.tr (H. Selcuk) \\ ${ }^{b}$ Izmir Institute of Technology, Faculty of Engineering, Department of Environmental Engineering, Urla, Izmir, Turkey, \\ email: haticeokten@iyte.edu.tr (H.E.Okten)
}

Received 5 May 2017; Accepted 27 December 2017

\section{A B S T R ACT}

We applied ozonation, metal coagulation (ferric chloride and alum), polymer treatment (Polyethylene polyamine, PP, and Cyanoguanidine Polymer, CP) and their combinations for decolorization of biologically treated textile wastewater (BTTWW). Wastewater samples were taken from effluent stream of an activated sludge treatment system in a synthetic-cotton textile factory. Absorbance, color, chemical oxygen demand (COD) measurements were done to determine optimum conditions. At coagulation experiments, neither ferric chloridenoralum decreased the color parameter below the discharge standard. Ozonation was found to be efficient in removing color from BTTWW as color degradation reached steady-state after $10 \mathrm{~min}$. However color standard was metai higher ozone dosages $(20 \mathrm{~min})$. Polymer coagulation $(200 \mathrm{mg} / \mathrm{L})$ was found to be practical in removing color from BTTWW. Ozonation prior to polymer coagulation (pre-ozonation) not only improved the color removal efficiency but also decreased the required polymer dosage by $75 \%$. Operational costs of ozonation, PP and pre-ozonation-subsequently PP were found to be $0.37 € / \mathrm{m}^{3}, 0.50 € / \mathrm{m}^{3}$, and $0.26 € / \mathrm{m}^{3}$, respectively.

Keywords: Textile industry; Decolorization; Ozonation; Coagulants; Cost analysis

\section{Introduction}

The world's population continues to increase dramatically and it is expected to reach 8.2 billion in 2050 [1]. An immense pressure is projected on urban and industrial water demands with a corresponding increase in wastewater volume. In fact, several countries have already attained limits of their water supplies [2,3]. Water scarcity has already affected main provision of drinking water along with other sectors such as agriculture, industry, and energy. The equilibrium between water demand and water availability is under pressure in many countries. Development of new cost-effective wastewater treatment and reuse technologies is vital to cope with increasing water demands and to ensure water supply for sustainable industrial activities. Thus numerous new reuse sys-

${ }^{*}$ Corresponding author. tems have been tested at pilot scale to attain zero waste approach in water intensive industries.

The textile industry is not only water intensive but also uses a great amount of hazardous chemicals such as dyes, detergents, solvents, surfactants, biocides, chlorine, etc. [4-7]. Types of dyes and additives used in a given production line may change on a daily basis. Thus, chemically or biologically treated textile wastewater is a changing mixture of dyes and additives used in wet processes. In the cotton and synthetic textile sectors, $50-75 \%$ of total dye consumption comes from reactive dyes. As a consequence, textile wastewater contains high levels of toxic organic pollutants, which translates into high chemical oxygen demand (COD) values and low biodegradability [8,9]. The complex character of textile industry wastewater needs to be handled carefully for both effluent toxicity and aesthetic problems. Many textile industries have facilitated biological treatment

Presented at the 3rd International Conference on Recycling and Reuse, 28-30 September 2016, Istanbul, Turkey

1944-3994 / 1944-3986 @ 2017 Desalination Publications. All rights reserved. 
to remove organic matter from their wastewater. Effluents of these treatment plants still contain residual azo dyes which give color to effluent discharges, have mutagenic/ carcinogenic effects on organisms and are toxic to aquatic life. Colored textile wastewater may be toxic even after conventional chemical or biological treatment. Also commercial membrane reuse systems are still not in practice at textile sector due to the fouling effects of non-biodegradable dyes. Thus development of treatment methods that can remove the remaining refractory dyes in BTTWW are required.

Advanced oxidation processes (AOPs) are powerful in degradation of non-biodegradable or toxic pollutants. Ozonation, $\mathrm{UV} / \mathrm{H}_{2} \mathrm{O}_{2}, \mathrm{TiO}_{2} / \mathrm{UV}$, Fenton's reagent, photo-Fenton, nano particles, photo electro catalytic and electro-chemical oxidation are able to remove toxicity and color from textile wastewaters $[6,7,10-16]$. In order to reuse BTTWW, ozonation, coagulation with ferric chloride, alum, anionic polymers and their dual implementations are the commonly favored methods prior to membrane filtration $[13,17,18]$. However, while ozonation is efficient for soluble dyes, coagulation is feasible for disperse dyes. Success of both ozonation and coagulation process depends on the types of dyes and salts, concentration of radical scavengers and thus nature of textile fabric.

Coagulation/flocculation of water-soluble dyes is challenging as high solubility adds to the complexity of coagulation process [19]. Despite drawbacks such as sludge production and high residual inorganic concentrations, inorganic Al-based coagulants and ferric salts are commonly used for both water and wastewater treatment [20]. In addition, they are sufficient for decolorization of secondary treated textile wastewaters [21]. Since coagulation/ flocculation is cost effective and efficient in color removal for a wide range of dyes, it becomes promising for treating textile wastewater [22]. Sludge production can also be minimized by optimizing process parameters and selecting the suitable coagulant. In recent years, national/international legislations about color parameter forced textile industry to apply decolorization processes before discharge. As metal coagulation was ineffective in meeting the national color standard, textile industry has started to use synthetic coagulants following biological treatment of wastewater. However, there is limited literature on single use of polymeric chemicals as coagulants. Therefore, evaluation of optimum conditions for single use of polymeric coagulants for different types of dyes in real textile wastewater is necessary.

Ozonation is known as a process without sludge production. However, ozonation is suitable for decolorization rather than mineralization. Ozonation is expensive due to its high energy consumption so generally it serves as a pre-treatment step when coupled with other processes [23]. Pre-ozonation enhances coagulation performance by destabilizing dye molecules to generate larger flocs due to stronger bridging adsorption ability. While ozone enhanced coagulation by metal salts is very well studied in the literature $[19,20,24]$, there is a limited number of studies on single and combined PP and CP polymer applications with or without pre-ozonation. Synthetic polymers enlarge metal flocs by sweeping floc generation and bridging adsorption mechanisms. Polyethylene polyamine (PP) and Cyanoguanidine Polymer (CP) are cost-effective coagulants for synthetic polymer coagulation of secondary treated tex- tile wastewater [25]. In this study, we investigated color removal efficiencies and operational costs for ozonation, metal and polymeric coagulation, and their combinations in real biologically treated textile wastewater.

\section{Material and methods}

\subsection{Biologically treated textile wastewater (BTTWW)}

BTTWW samples were obtained from the textile plant located in Torbali area of Izmir, Turkey. Highly colored effluent of biological treatment plant of a synthetic-cotton textile factory was used in the experiments. In the factory, reactive dyeing, washing, rinsing, and finishing wastewaters are the main sources of wastewater. Samples stored at $4^{\circ} \mathrm{C}$ to keep chemical composition intact.

\subsection{Analytical methods}

COD, total organic carbon (TOC), alkalinity, total suspended solids (TSS) and volatile suspended solids (VSS) were analyzed to determine sample characteristics as described in Stand art Methods [26]. Hach DR5000 UV-Vis spectrophotometer was used for color and absorbance measurements. Color values were compared according to national regulation value $(280 \mathrm{Pt} / \mathrm{Co})$ given in Turkish National Regulation of Water Pollution Control [27]. pH and conductivity measurements were done with $\mathrm{HACH}$ HQ40D portable multi-meter. TOC measurements were carried out with Shimadzu TOC-CPN TOC analyzer.

\subsection{Ozonation and operational cost}

The ozone was generated with a Sander Model 300.5 ozone generator. Pure oxygen with a flow rate of $500 \mathrm{NL} / \mathrm{h}$ was fed to the generator. System worked at $250 \mathrm{~mA}$ current. Generated ozone had a flow rate of $4.5 \mathrm{~g}$ ozone $/ \mathrm{h}$ and a concentration of $14 \mathrm{~g}$ ozone $/ \mathrm{m}^{3}$. Generated ozone was fed to a glass reactor of $1 \mathrm{~L}$ via a ceramic diffuser for homogeneous distribution. Ozonation performance was monitored for various operation periods up to $20 \mathrm{~min}$. Consumed ozone was determined to calculate operational ozone cost as previously reported $[13,28]$.

\subsection{Coagulation and operational cost}

In this study, aluminum sulfate $\left(\mathrm{Al}_{2}\left(\mathrm{SO}_{4}\right)_{3} \cdot 18 \mathrm{H}_{2} \mathrm{O}\right)$ and ferric chloride $\left(\mathrm{FeCl}_{3}\right)$ were selected as primary metal coagulants. Polyethylene polyamine (PP) and cyanoguanidine polymer $(\mathrm{CP})$ were obtained from resellers. Optimum dosage experiments of both metal and polymer coagulants were carried out with a Wise Stir multiple stirrer jar-test device. Dosages tested for metal and polymer coagulants were $50,100,200,300$, and $500 \mathrm{mg} / \mathrm{L}$. After the addition of coagulants to $500 \mathrm{~mL}$ of wastewater samples, device was set to rapid mixing at $120 \mathrm{rpm}$ for $5 \mathrm{~min}$ and then velocity of the paddles was brought down to $30 \mathrm{rpm}$ for flocculation of $25 \mathrm{~min}$. Supernatant samples were collected after $30 \mathrm{~min}$ of settling. Then we carried out color and COD measurements to calculate removal efficiencies. Optimum dosages of alum, ferric chloride, PP and CP were calculated to determine operational costs of coagulants. 


\section{Results}

\subsection{Characterization of highly colored synthetic-cotton textile wastewater}

Due to reactive dye residuals and remaining COD concentration in the highly colored BTTWW, some of the decolorization or membrane treatment methods may not be feasible for reuse. Thus, degradation of color and COD in BTTWW is vital before sending wastewater to membrane processes [29]. Effluent characterization of full scale biological treatment plant is given in Table 1. COD concentration was reduced to $120 \mathrm{mg} / \mathrm{L}$ and color was measured as 3500 $\mathrm{Pt} / \mathrm{Co}$ in the effluent of biological treatment plant. It is not possible to discharge BTTWW directly without tertiary treatment.

\subsection{Treatment of BTTWW by metal coagulants}

Fig. 1 shows optimum alum $(300 \mathrm{mg} / \mathrm{L})$ and $\mathrm{FeCl}_{3}$ (500 mg/L) coagulation dosages for color removal. Metal coagulation experiments were carried out at various coagulant dosages in the range of $50 \mathrm{mg} / \mathrm{L}$ to $500 \mathrm{mg} / \mathrm{L}$. Color

Table 1

Characterization of biologically treated textile wastewater

\begin{tabular}{ll}
\hline Parameter & Result \\
\hline $\mathrm{pH}$ & $7.85 \pm 0.4$ \\
Conductivity, mS/cm & $13.36 \pm 2.0$ \\
Color, Pt/Co & $3500 \pm 260$ \\
$\mathrm{COD}, \mathrm{mg} / \mathrm{L}$ & $120 \pm 16$ \\
$\mathrm{TOC}, \mathrm{mg} / \mathrm{L}$ & $35 \pm 2.3$ \\
Alkalinity, mg/L & $120 \pm 9.0$ \\
TSS, mg/L & $85 \pm 12$ \\
Hardness, $\mathrm{mg} \mathrm{CaCO}_{3} / \mathrm{L}$ & $950 \pm 48$ \\
\hline
\end{tabular}

removal efficiency by alum was only $58 \%$, which was not enough to meet the discharge standards (Fig. 2). The highest COD removal efficiency of $58 \%$ was achieved with $300 \mathrm{mg} / \mathrm{L}$ alum dosage (Table 2).

In the literature, it is reported that although iron chloride can remove $79-82 \%$ of reactive dyes, color removal efficiency remains at $58-64 \%$ [30]. This study shows similar results based on color removal with iron chloride. Coagulation studies with $\mathrm{FeCl}_{3}$ did not meet the national standard for color parameter. Color values after $\mathrm{FeCl}_{3}$ coagulation were over $280 \mathrm{Pt} / \mathrm{Co}$ even when the highest dosage was applied (Fig. 2). The highest COD removal, 67\%, was achieved with the highest $\mathrm{FeCl}_{3}$ dosage as shown in Table 2. However, $\mathrm{FeCl}_{3}$ dosage over $200 \mathrm{mg} / \mathrm{L}$ was not cost effective due to sludge production.

\subsection{Coagulation with commercial polymer coagulants}

Various CP and PP dosages (50-500 $\mathrm{mg} / \mathrm{L}$ ) were applied in jar-test experiments to find out optimum dosage for decolorization of BTTWW (Figs. 3 and 4). Coagulation with PP have produced slightly better results than with $\mathrm{CP}$. $\mathrm{PP}$ and $\mathrm{CP}$ coagulation results differed when COD removal efficiencies were considered. $47 \%$ and $18 \%$ COD removals were achieved at $\mathrm{CP}$ and PP experiments, respectively (Table 2).

\subsection{Ozone application for the decolorization of BTTWW}

Ozone has been applied successfully for removal of color from textile wastewater streams as well as in other industrial wastewater processes. There are numerous studies on combined applications of ozone and other treatment alternatives, such as coagulation and other advanced oxidation processes [28,31,32]. Fig. 5 shows the effect of ozonation on color degradation for different ozonation periods. Initial color level of $3500 \mathrm{Pt} / \mathrm{Co}$ decreased sharply during the first $5 \mathrm{~min}$ into ozonation and then a second decrease
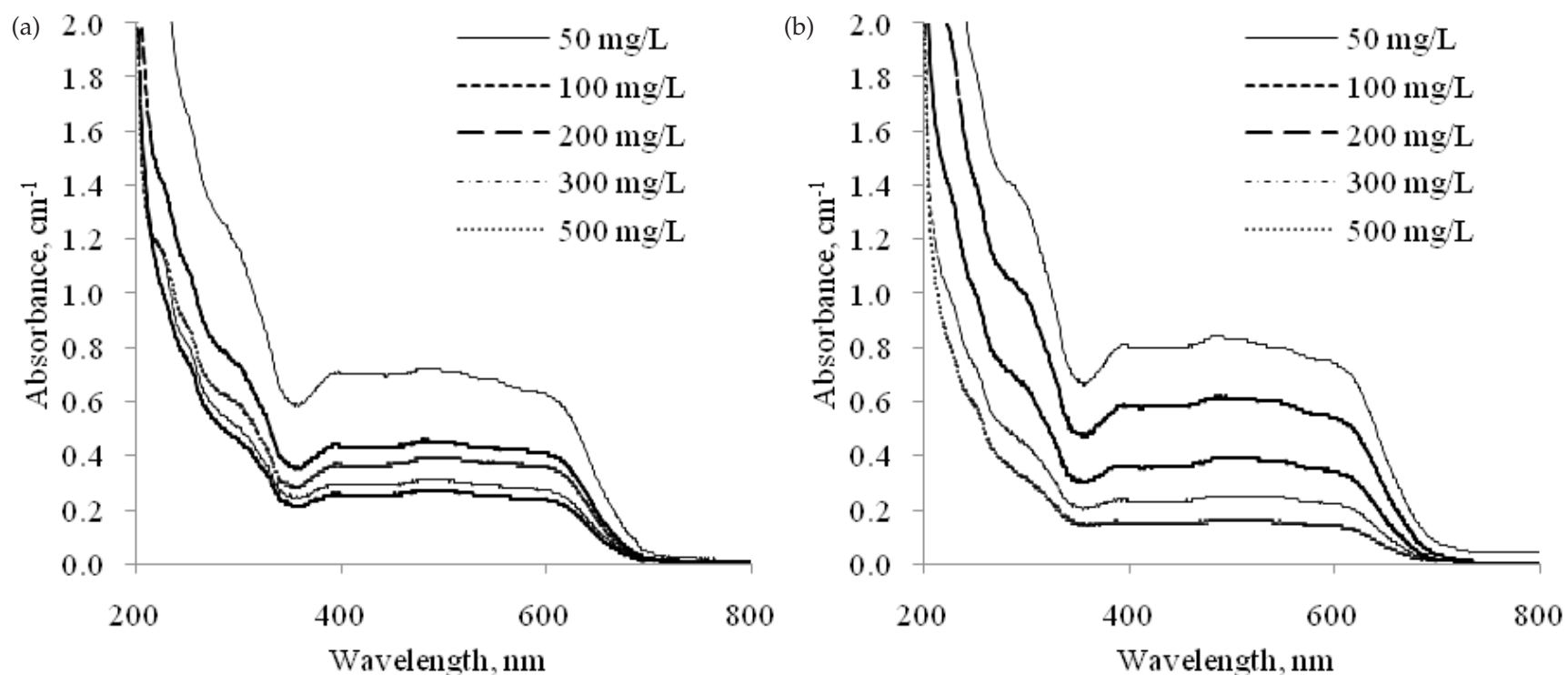

Fig. 1. Absorbance values after coagulation of BTTW after each single treatment. a) Alum b) Ferric Chloride. 
Table 2

Effect of coagulation and ozonation on COD removal efficiencies $(\%)$ from BTTWW

\begin{tabular}{|c|c|c|c|c|c|c|c|}
\hline \multirow{2}{*}{$\begin{array}{l}\text { Coagulant } \\
\text { dose } \\
(\mathrm{mg} / \mathrm{L})\end{array}$} & \multirow{2}{*}{$\begin{array}{l}\text { Alum } \\
(\%)\end{array}$} & \multirow{2}{*}{$\begin{array}{l}\mathrm{FeCl}_{3} \\
(\%)\end{array}$} & \multirow{2}{*}{$\begin{array}{l}\mathrm{CP} \\
(\%)\end{array}$} & \multirow{2}{*}{$\begin{array}{l}\mathrm{PP} \\
(\%)\end{array}$} & \multicolumn{3}{|c|}{ Ozonation (\%) } \\
\hline & & & & & $\begin{array}{l}5 \\
\min \end{array}$ & $\begin{array}{l}10 \\
\min \end{array}$ & $\begin{array}{l}20 \\
\min \end{array}$ \\
\hline 0 & - & - & - & - & 27 & 26 & 33 \\
\hline 50 & 31 & 24 & 2 & - & & & \\
\hline 100 & 50 & 47 & 35 & 18 & & & \\
\hline 200 & 53 & 62 & 47 & 18 & & & \\
\hline 300 & 58 & 64 & 32 & - & & & \\
\hline 500 & 47 & 73 & 8 & - & & & \\
\hline
\end{tabular}

(a)
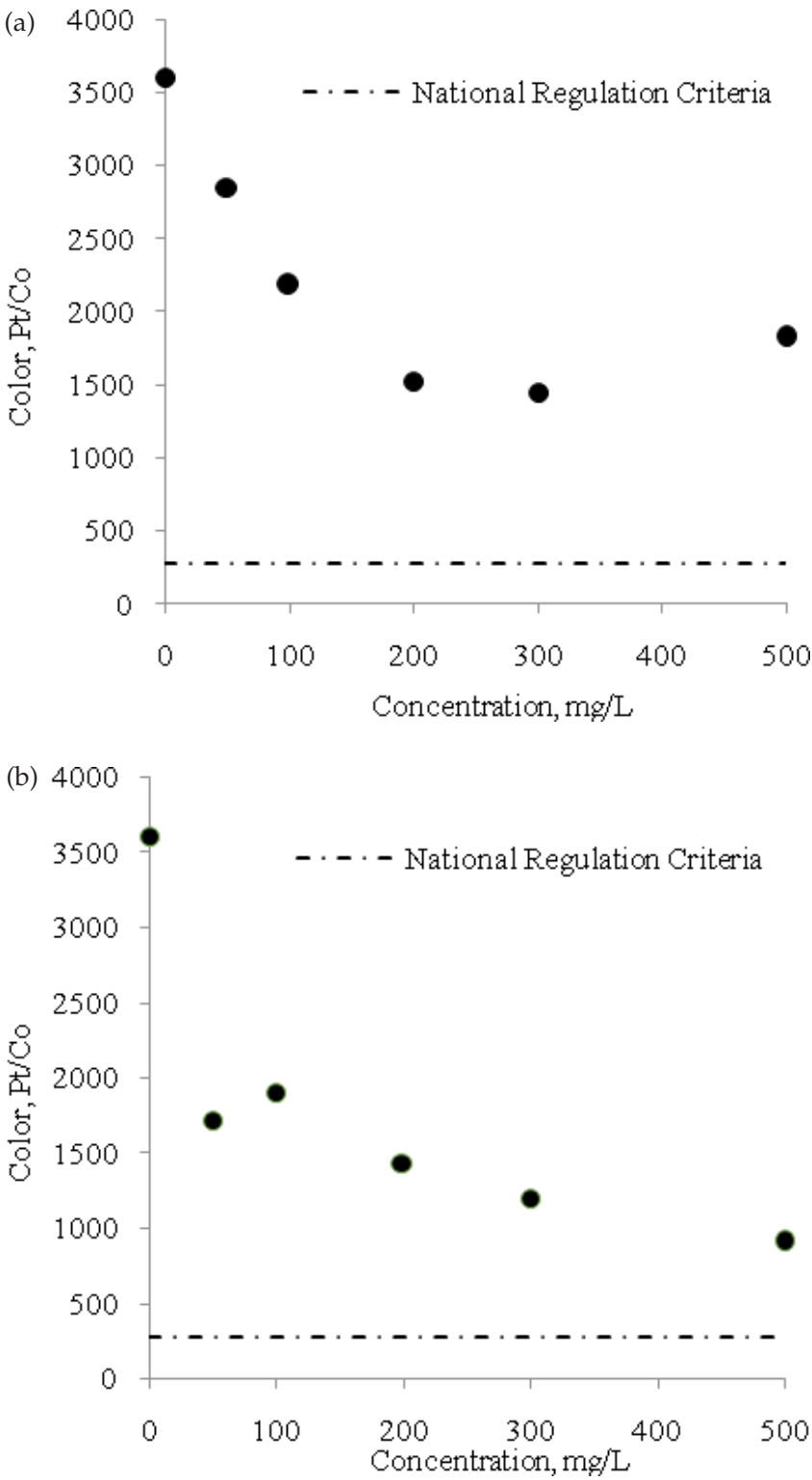

Fig. 2. Effect of coagulation on color removal from BTTW after each single treatment. a) Alum b) Ferric Chloride.
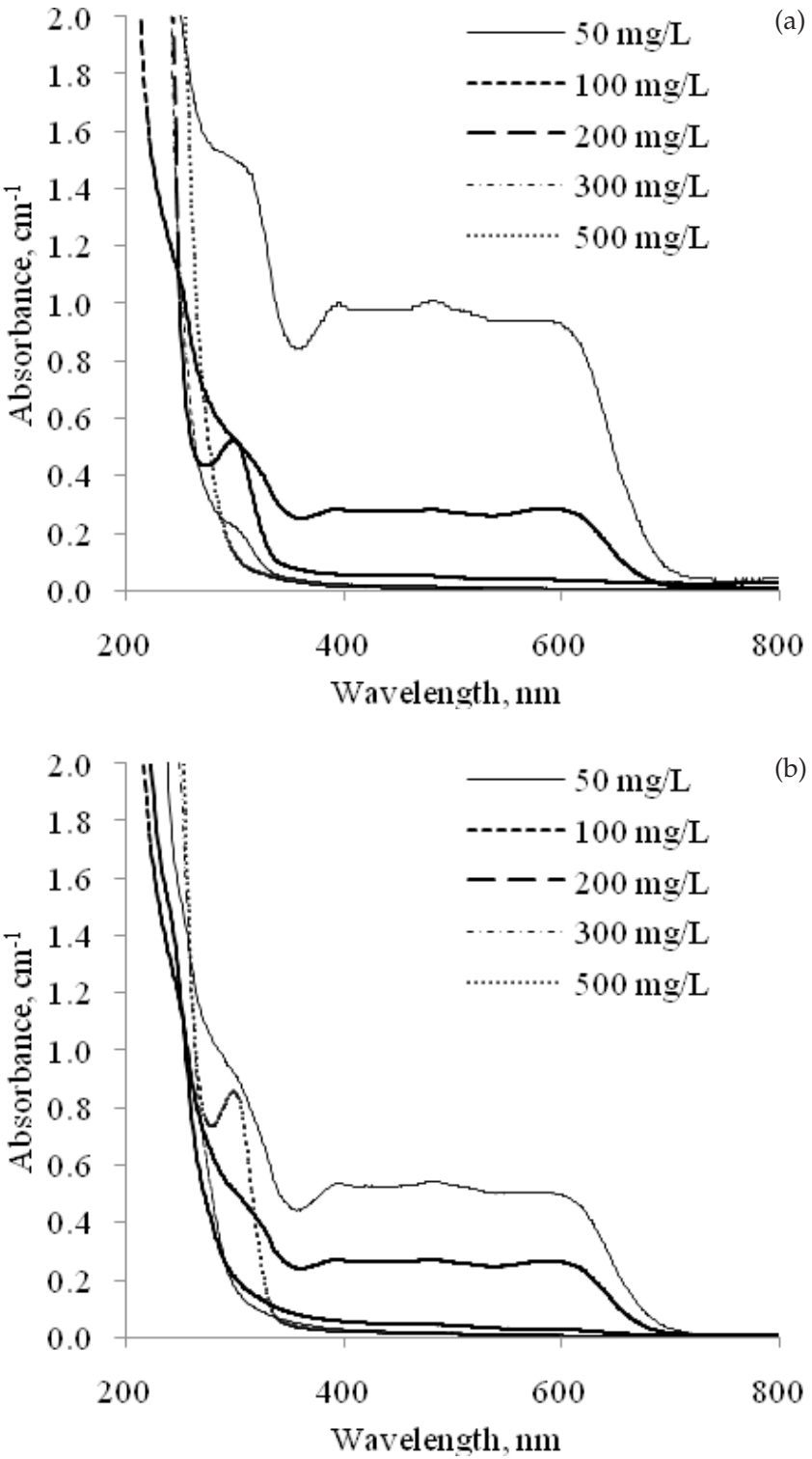

Fig. 3. Absorbance values after coagulation of BTTW after each single treatment. a) $\mathrm{CP}$ b) PP.

was observed from $10 \mathrm{~min}$ to $20 \mathrm{~min}$. (Fig. 5). However, color level was still higher than the discharge standard (280 $\mathrm{Pt} / \mathrm{Co}$ ) until $15^{\text {th }} \mathrm{min}$. COD removal rates fluctuated around $26-33 \%$ during ozonation (Table 2). Since ozonation was done as a pretreatment, complete removal of color was not required. Therefore $5 \mathrm{~min}$ and $10 \mathrm{~min}$ ozonation times were selected to be tested at coagulation studies.

\subsection{The Effect of Pre-Ozone application on coagulation}

Membrane processes consisting of UF, NF, RO and their soluble combinations have been applied to treat the textile wastewater. However, disadvantages such as brine generation, organic and biological foulings and thus low flux efficiency on membrane hampers the direct use of membrane-based wastewater treatment systems. Pre-ozonation is known as one of the membrane pre-treatment processes. 



Fig. 4. Effect of polymer coagulation on color removal from BTTW after each single treatment. a) CP b) PP.

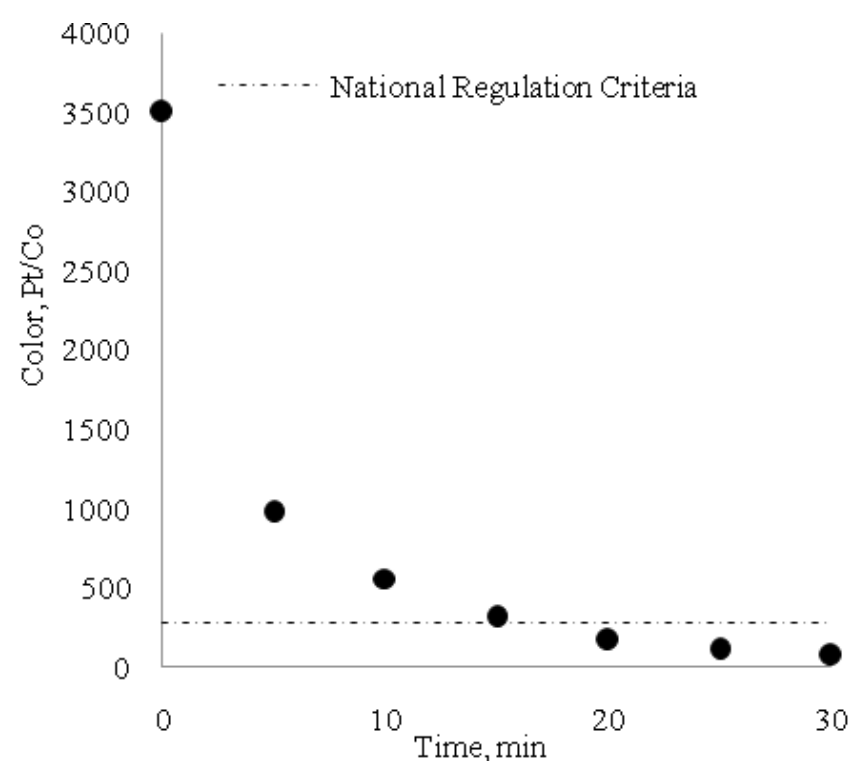

Fig. 5. Effect of ozonation on color removal.

Ozone destructs soluble dye molecules resulting in decolorization of textile wastewaters. Efficiencies of sole-ozonation, pre-ozonation, and post-ozonation depend on the type of wastewater and its physico-chemical properties. In this study, the effect of pre-ozonation on the metal and polymer coagulations was investigated comparatively.

\subsubsection{Effect of pre-ozonation on the metal and polymer coagulation}

Metal coagulation alone was not effective for color removal from BTTWW. Furthermore, $\mathrm{CP}$ and PP polymer coagulations resulted in high sludge production and low COD removal. Results showed that polymer coagulation might be a feasible method for decolorization but it might not be a feasible one for COD removal. Therefore, $\mathrm{CP}$ and PP coagulations could not be viable pre-treatment options for membrane reuse system due to high COD concentration that might cause fouling on membrane surface. Lee and colleagues [33] reported that application of pre-ozonation enlarged small particles in the wastewater as a result of increased performance for both UF and $\mathrm{RO}$ membrane by pre-ozonation. Ozone might also destruct dye molecules and form smaller soluble molecules which increased COD values during decolorization of textile wastewaters [13]. Besides, ozone may cause a decrease in particle stability and thus, it may increase the efficiency of coagulation process [34]. The effect of pre-ozonation on the performance of coagulation process depends on not only type of coagulant but the nature of textile wastewater as well. Therefore, in order to evaluate dual treatment process for synthetic-cotton textile industry, 5 and $10 \mathrm{~min}$ of pre-ozonation periods were applied to enhance metal and polymer coagulation efficiencies (Figs. 6-11).

Metal and polymer coagulation experiments were conducted under the same conditions that were done for single coagulation. Results of color removal were given in Figs. 6-11. As can be followed from Fig. 6 and Table 3, pre-ozonation did not enhance color and COD removal in alum and ferric chloride coagulation processes and as a result color level did not meet color standard. The inhibitory effect of pre-ozonation was observed on the COD removal. After pre-ozonation COD removal decreased slightly (around $8 \%$ ) in both metal coagulation treatments. Results reflected that ozone had no positive effect on metal coagulation to remove COD from highly colored BTTWW. Additionally, pre-ozonation might have inhibitory effect on COD removal thus pre-ozonation following coagulation mightnot bea pre-treatment method of membrane wastewater reuse systems.

The color degradation was at steady state in ozonation process. Application of 5 and $10 \mathrm{~min}$ pre-ozonation decreased optimum polymer dosages for both coagulants from approximately $200 \mathrm{mg} / \mathrm{L}$ to 165 and $50 \mathrm{mg} / \mathrm{L}$, respectively (Table 4). The CP dosage of $50 \mathrm{mg} / \mathrm{L}$ was found to be sufficient to meet 

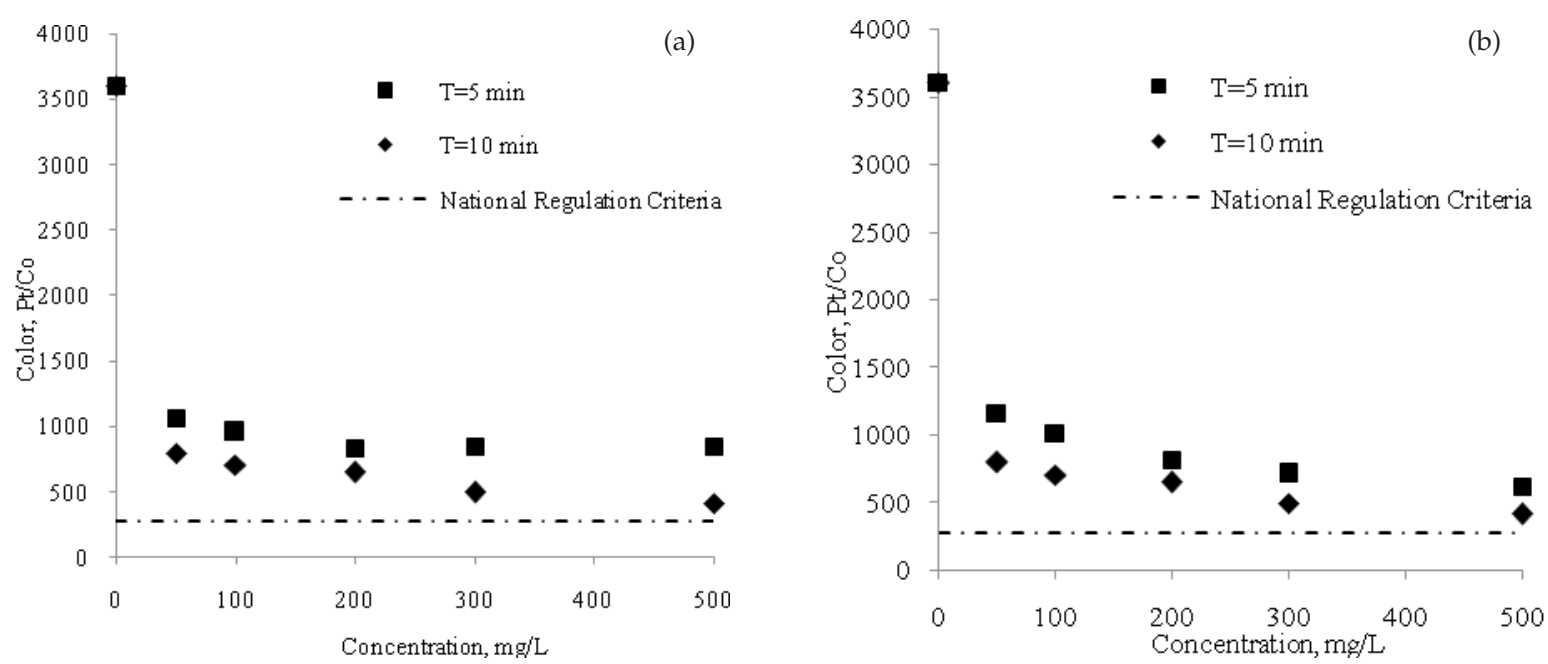

Fig. 6. Effect of pre-ozonation on color removal by coagulation from BTTW after each single treatment. a) Alum b) Ferric Chloride.
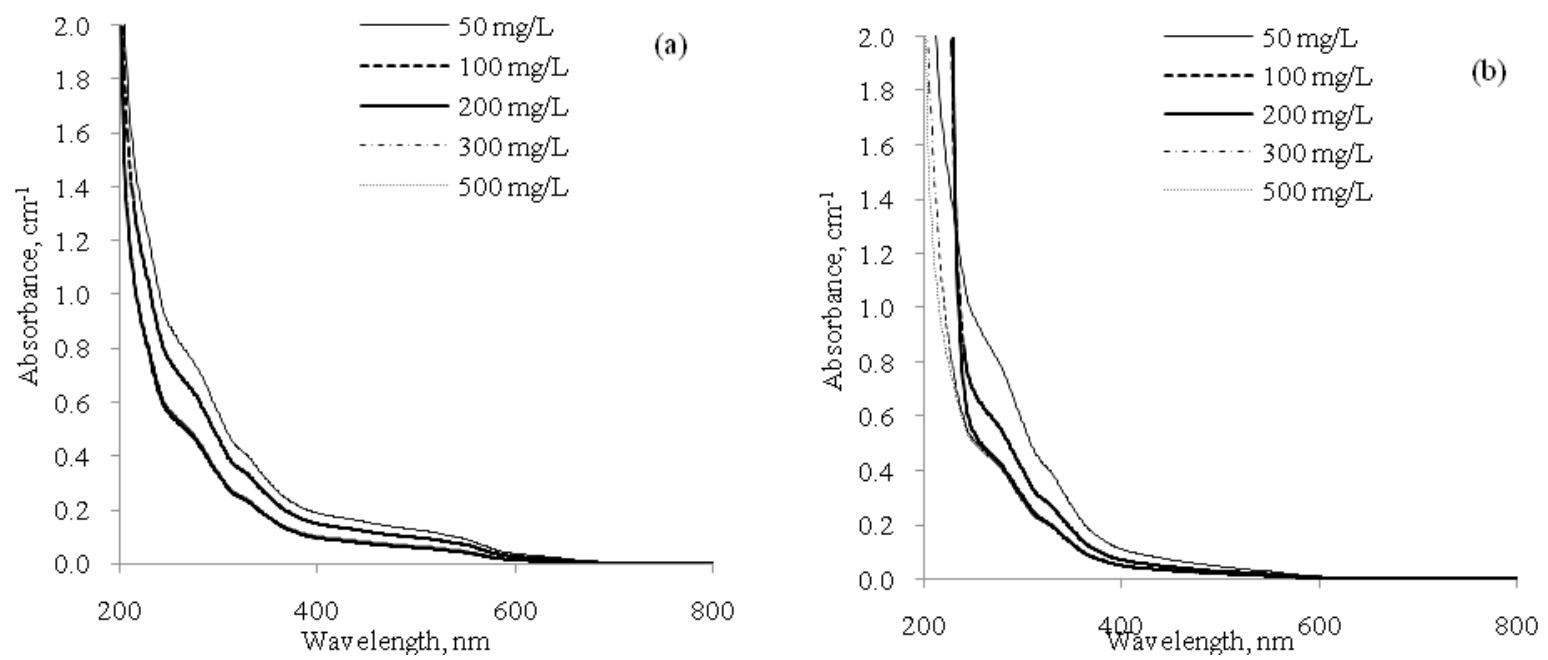

Fig. 7. Absorbance values of BTTW after each single and combined treatment (Ozonation $\left.-\mathrm{Al}_{2}\left(\mathrm{SO}_{4}\right)_{3} \cdot 18 \mathrm{H}_{2} \mathrm{O}\right)$.

(a). Ozonation time (OT.) $-5 \mathrm{~min}$. followed by coagulation (b). OT. $-10 \mathrm{~min}$. followed by coagulation.
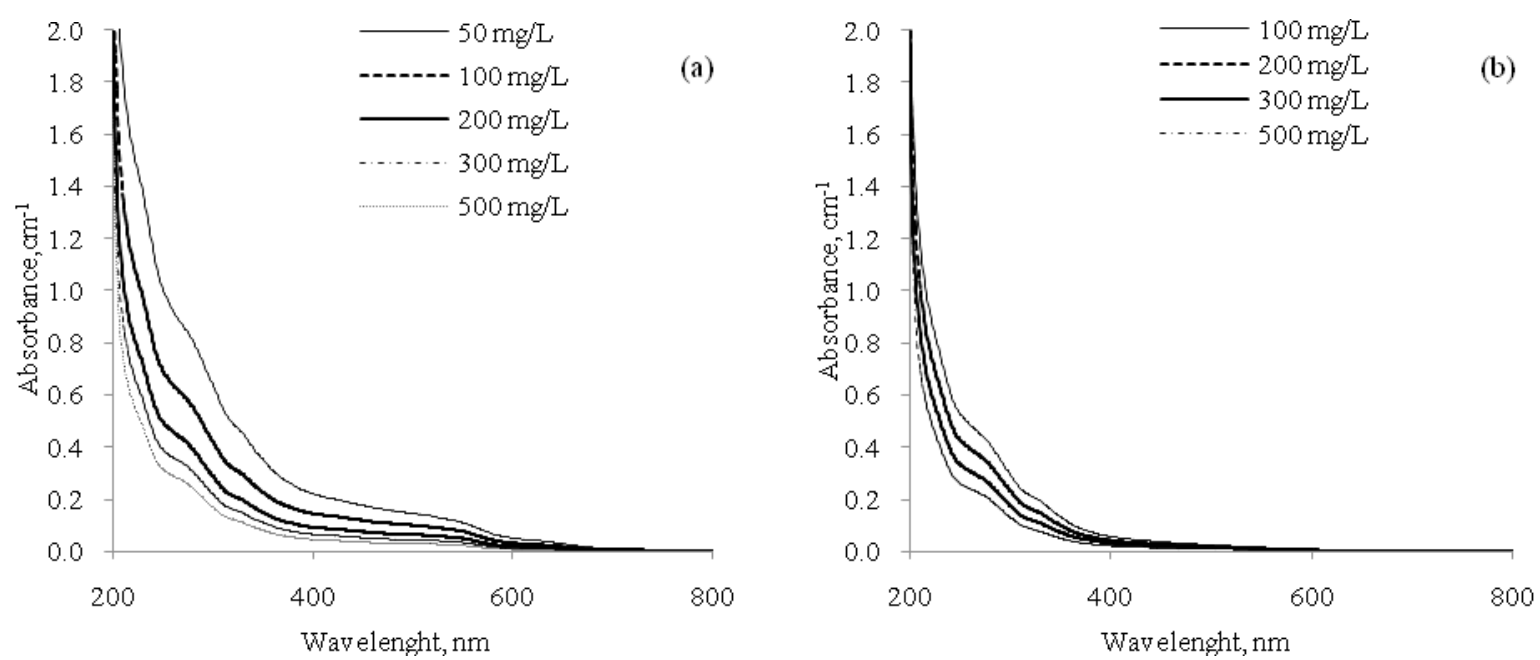

Fig. 8. Absorbance values of BTTWW after each individual and combined treatment $\left(\mathrm{Ozonation}-\mathrm{FeCl}_{3}\right)$.

(a). Ozonation time (OT.) $-5 \mathrm{~min}$. followed by coagulation (b). OT. $-10 \mathrm{~min}$. followed by coagulation. 

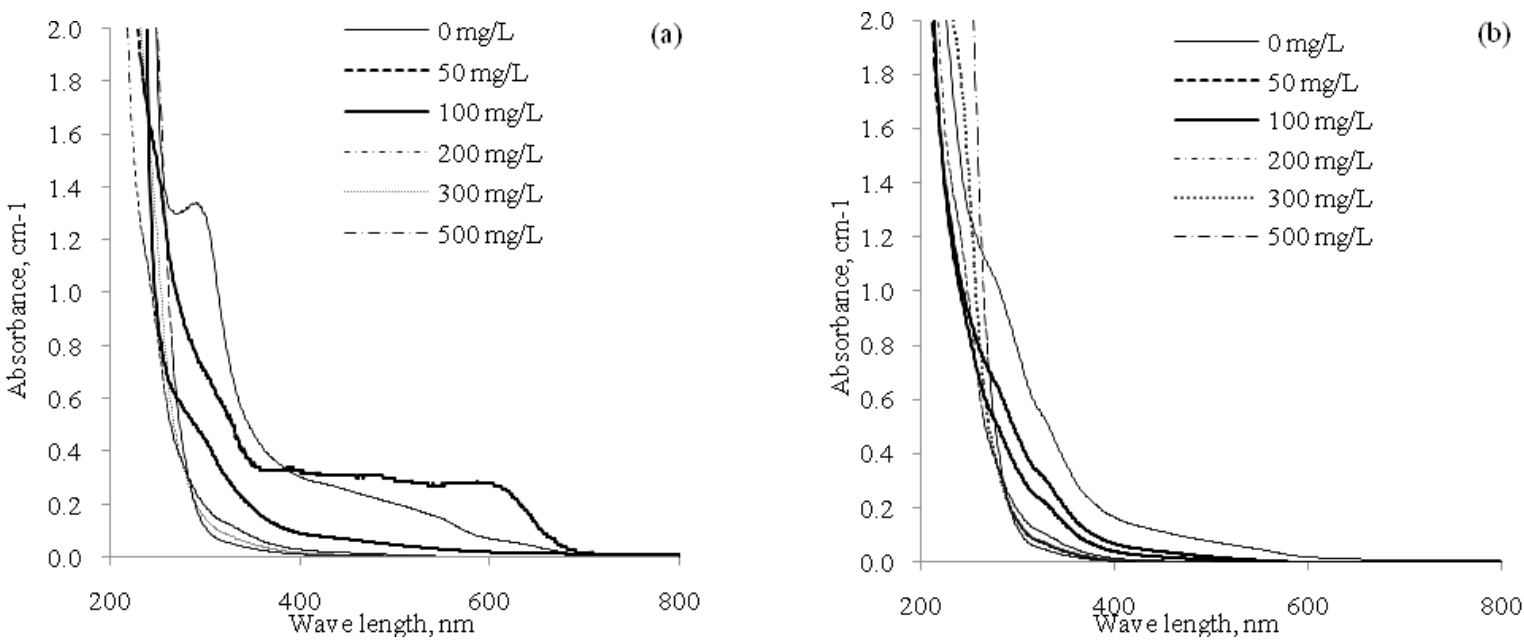

Fig. 9. Absorbance values of BTTWW after each individual and combined treatment (Ozonation - CP).

(a). Ozonation time (OT.) $-5 \mathrm{~min}$. followed by coagulation (b). OT. $-10 \mathrm{~min}$. followed by coagulation.
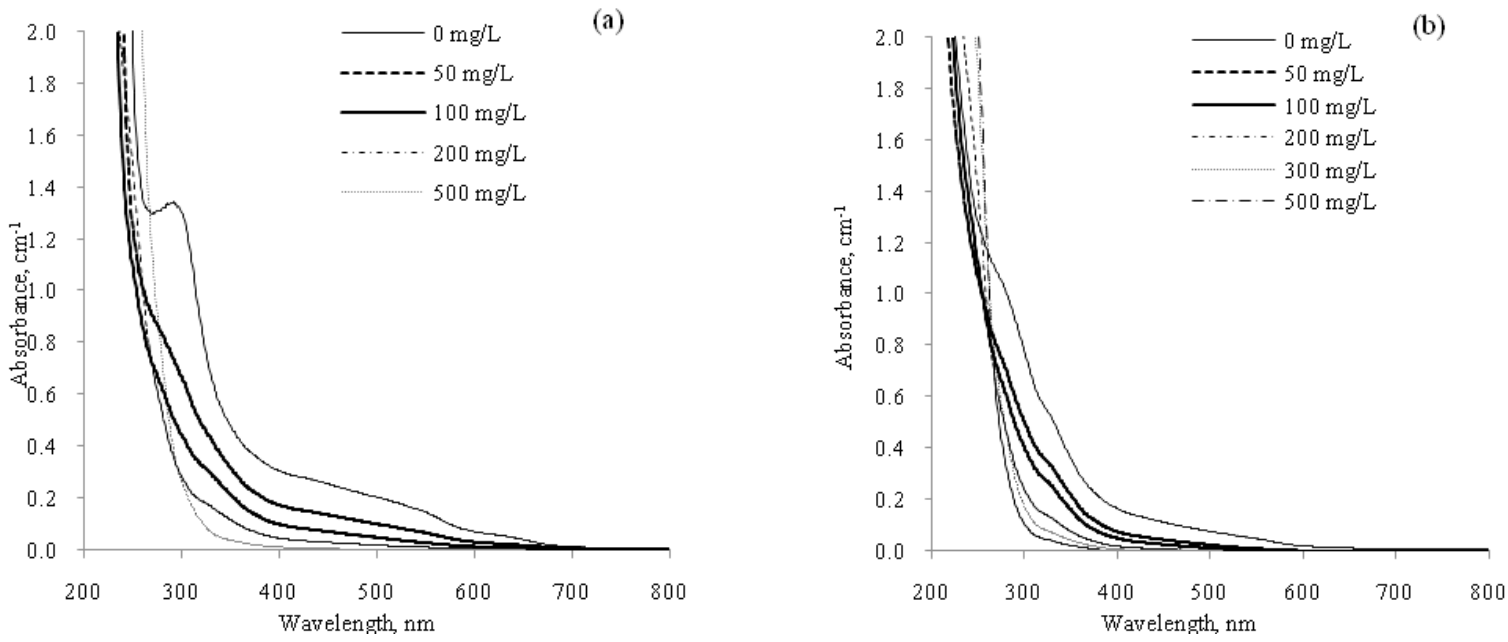

Fig. 10. Absorbance values of BTTWW after each individual and combined treatment (Ozonation - PP).

(a). Ozonation time (OT.) -5 min. followed by coagulation (b). OT. -10 min. followed by coagulation.
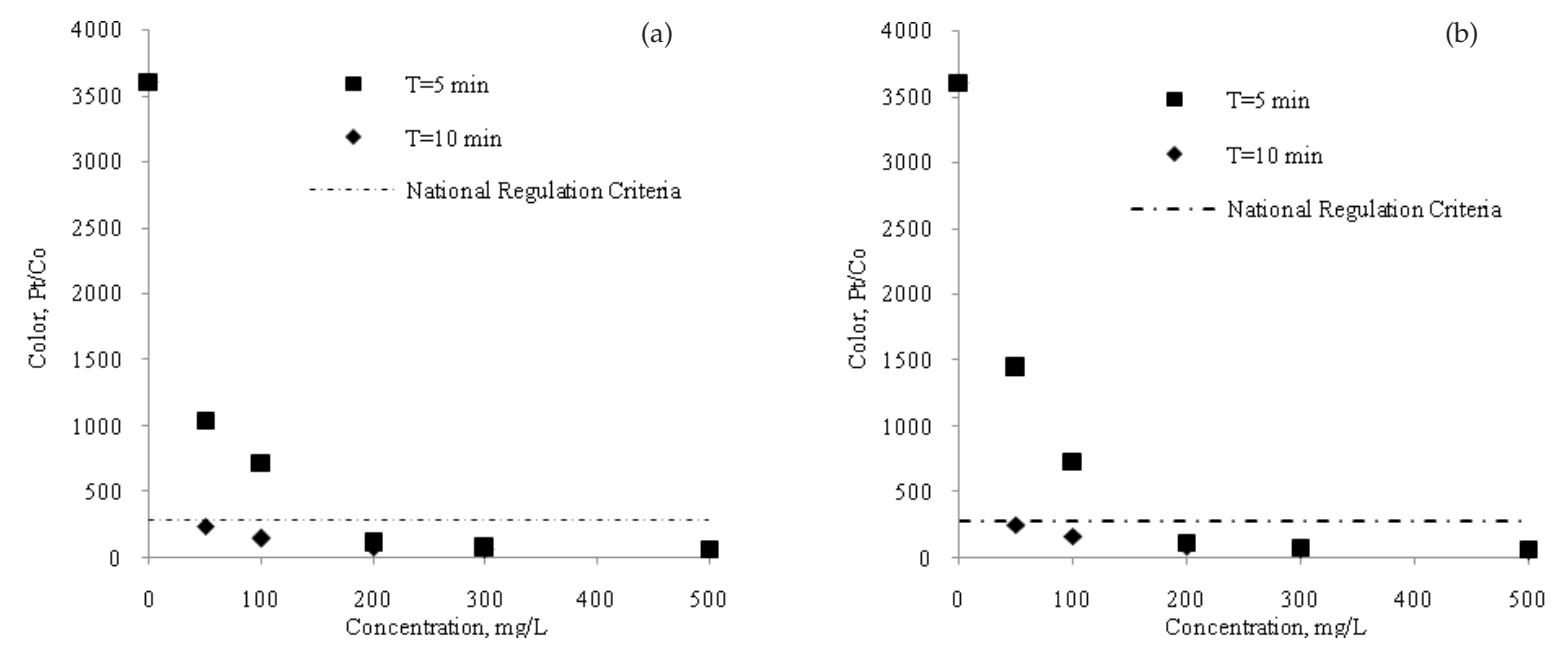

Fig. 11. Effect of polymer coagulation after pre-ozonation on color removal from BTTW after each single treatment. a) CP b) PP. 
Table 3

COD removal efficiencies (\%) from BTTWW after 5 and 10 min pre-ozonation time with various metallic and polymeric coagulant

\begin{tabular}{|c|c|c|c|c|c|c|c|c|}
\hline \multirow{2}{*}{$\begin{array}{l}\text { Coagulant } \\
\text { Dose } \\
(\mathrm{mg} / \mathrm{L})\end{array}$} & \multicolumn{2}{|c|}{ Alum (\%) } & \multicolumn{2}{|c|}{$\mathrm{FeCl}_{3}(\%)$} & \multicolumn{2}{|c|}{$\mathrm{CP}(\%)$} & \multicolumn{2}{|c|}{ PP (\%) } \\
\hline & $\begin{array}{l}5 \\
\min \end{array}$ & $\begin{array}{l}10 \\
\mathrm{~min}\end{array}$ & $\begin{array}{l}5 \\
\min \\
\end{array}$ & $\begin{array}{l}10 \\
\min \end{array}$ & $\begin{array}{l}5 \\
\min \\
\end{array}$ & $\begin{array}{l}10 \\
\min \end{array}$ & $\begin{array}{l}5 \\
\min \\
\end{array}$ & $\begin{array}{l}10 \\
\min \end{array}$ \\
\hline 50 & 31 & 44 & 43 & 26 & 13 & 25 & 3 & - \\
\hline 100 & 58 & 50 & 55 & 3 & 38 & 35 & 24 & 14 \\
\hline 200 & 52 & 61 & 61 & - & 28 & 28 & 16 & 3 \\
\hline 300 & 53 & 58 & 60 & - & 30 & 23 & 11 & - \\
\hline 500 & 49 & 41 & 60 & - & - & - & - & - \\
\hline
\end{tabular}

Table 4

Optimum dosages and operational costs of applied treatments

\begin{tabular}{llll}
\hline Method & & $\begin{array}{l}\text { Optimum } \\
\text { dosage } \\
\text { (mg/L) }\end{array}$ & $\begin{array}{l}\text { Unit } \\
\text { operational } \\
\text { cost }\left(€ / \mathrm{m}^{3}\right)\end{array}$ \\
\hline Ozonation $\left(20 \mathrm{~min}^{*}\right)$ & 384 & 0.37 \\
PP & 190 & 0.50 \\
PP with Pre-Ozonation & $\mathrm{T}: 5 \mathrm{~min}$ & 165 & 0.36 \\
PP with Pre-Ozonation & $\mathrm{T}: 10 \mathrm{~min}$ & 50 & 0.27 \\
CP & & 180 & 0.45 \\
CP with Pre-Ozonation & T: 5 min & 165 & 0.34 \\
CP with Pre-Ozonation & T: $10 \mathrm{~min}$ & 50 & 0.26 \\
\hline
\end{tabular}

*Ozonation time to provide color standards.

desired color limit. However, polymer coagulation following pre-ozonation showed detrimental effects on removal of COD. COD removal efficiencies decreased around $40 \%$ and $80 \%$ for pre-ozonated CP and PP coagulation, respectively (Tables 2,3). Results showed that dual system of ozonation and polymer coagulation might be practical for decolorization of BTTWW. However, it could not be advised as a pre-treatment method for wastewater reuse systems with membranes due to fouling problem.

\subsection{Cost of treatment}

In this study, chemical consumption and ozone production costs were taken into account for cost analysis of applied treatment methods. Operating costs were calculated according to the optimum coagulant and ozone dosages that met the color standard. Cost of electricity consumption for ozonation was calculated according to the electricity distribution fees in Turkey. The cost analysis of applied single and dual treatment methods are summarized in Table 4 . Unit operational cost for ozonation process was $0.37 € / \mathrm{m}^{3}$. In the literature cost predictions of a wide range, $0.20-1.38 € / \mathrm{m}^{3}$, were reported for polishing of BTTWW $[32,35]$. The range reflects that cost of ozonation may change depending on nature and color level of wastewater. Operating costs of coagulation process without ozonation were calculated as $0.5 € / \mathrm{m}^{3}$ and $0.45 € / \mathrm{m}^{3}$ for PP and $\mathrm{CP}$, respectively. Due to pre-ozonation, color removal efficiency was enhanced by $46 \%$ and operational treatment costs of polymer coagulations were reduced by $42 \%$ (Table 4 ). Operational costs were not calculated for metal coagulation since the effect of pre-ozonation was in significant.

\section{Conclusions}

Dyes, especially acidic and reactive dyes, cannot be removed with conventional treatment methods due to their microbial, chemical and photolytic degradation resistant structures [36,37]. Pre-treatment of the flow before membrane treatment shall be done to prevent membrane fouling $[38,39]$. Methods such as oxidation, pre-filtering, adsorption, and coagulation/flocculation have been studied as preliminary treatment methods for membrane filtration in the literature.

Coagulation was preferred in textile industry due to its low capital cost in treatment of produced wastewaters. However, sludge formation and low color removal are the two main issues regarding coagulation. Sludge treatment is an expensive process and sludge disposal poses a problem with increasing costs in landfill sites. Deficiency in color removal results in failing to meet the regulatory standards. Therefore, these disadvantages drive operators to couple coagulation with other treatment processes.

Coagulation helps the separation process of dyes in membrane treatment, prolonging service time of membrane. However, in efficient coagulation may accelerate membrane fouling. For this reason, pre-treatment methods shall be well evaluated and optimized before membrane treatment as cleaning of dye-fouled membranes is very difficult [40].

We evaluated treatment efficiencies of ozonation and metal/polymer coagulation along with their combinations at activated sludge effluents. The findings were discussed as follows;

- Degradation of color during ozonation was initially fast however decolored BTTWW did not meet color standard. Color standard was achieved by ozone doses over $15 \mathrm{~min}$. As expected, COD removal efficiency fluctuated around 25-35\% during ozonation [41].

- Pre-ozonation of BTTWW impeded COD removal efficiencies of both metal and polymer coagulations. COD removal rates decreased approximately $8 \%$ for metals, $40 \%$ for CP and $83 \%$ for PP after 10 min of ozonation.

- Ferric chloride and alum did not decrease color parameter below the standard at any experiment even with high dosages. In contrast to the previous studies [42], Ferric chloride was found to be better than alum as $62 \%$ and $53 \%$ COD removals were achieved, respectively. Similar color and COD removal efficiencies were also reported in the literature[18,43,44]. As reported by Arafat [21], metal salts failed to meet discharge standard for cotton-synthetic textile industry. Coagulation results achieved by $\mathrm{PP}$ and $\mathrm{CP}$ coagulants showed that polymer coagulation was feasible for decolorization of BTTWW. But it was not efficient in reducing COD concentrations. Cost analysis showed that it might not be a 
cost effective way to remove color when compared to the ozone-polymer coagulation dual treatment applications. On the other hand, residual toxicity of synthetic polymer was an issue due to its unreacted monomers, chemicals and their by-products. There is limited reported work on the fate and transport phenomena of polymers in the real wastewater treatment systems.

- $5 \mathrm{~min}$ of pre-ozonation helped to decrease optimum polymeric coagulant dosages and thus the cost of decolorization of BTTWW by polymer coagulants. Cost was reduced from 0.50 to $0.36 € / \mathrm{m}^{3}$ for PP and from 0.45 to $0.34 € / \mathrm{m}^{3}$ for CP. Also, $10 \mathrm{~min}$ of pre-ozonation reduced polymeric coagulant dosage (from almost $200 \mathrm{mg} / \mathrm{L}$ to $50 \mathrm{mg} / \mathrm{L}$ ) and cost (PP: from 0.50 to $0.27 € / \mathrm{m}^{3}$ and $\mathrm{CP}$ : from 0.45 to $\left.0.26 € / \mathrm{m}^{3}\right)$.

After coagulation net charge of flocs is normally zero. Depending on the treatment conditions, effluent of polymeric coagulation may be slightly negative or positive. Generally, color removal decreases with increase of dye solubility and dye concentration. $70 \%$ of total dye consumption in the cotton textile industry is reactive and reactive dyes are in the anionic form. Furthermore, high water solubility makes removing dyes from the water body more complicated. Also, membranes fouled with reactive dyes are very difficult to clean because interactions between reactive dye and membrane are strong [40]. Below the isoelectric point polyamide membranes have positive charge and can react with anionic dyes [45]. Besides, industrial reactive dyestuffs are not pure compounds but they contain many different additives and impurities. Dye structure and reactivity cause the optimum dosage of coagulant to differ. Therefore, it is important to use real biologically treated wastewater instead of synthetic ones for realistic optimization of treatment process. The result reflects the fact that single polymeric coagulation is not only an efficient method to meet color standards but also it may be used as pre-treatment prior to membrane processes. Thus, future studies will be conducted on the effect of polymer coagulation on the following membrane processes.

\section{References}

[1] D. UN, World population prospects: The 2015 revision, in, United Nations, Department of Economic and Social Affairs, Population Division New York, 2015.

[2] M. Pedro-Monzonís, A. Solera, J. Ferrer, T. Estrela, J. Paredes-Arquiola, A review of water scarcity and drought indexes in water resources planning and management, J. Hydrol., 527 (2015) 482-493.

[3] K.Schwabe, J. Albiac, J.D. Connor, R.M. Hassan, L.M. González, Drought in Arid and Semi-Arid Regions, Springer, 2015.

[4] I. Bisschops, H. Spanjers, Literature review on textile wastewater characterisation, Environ. Technol., 24 (2003) 1399-1411.

[5] V.M. Correia, T. Stephenson, S.J. Judd, Characterisation of textile wastewaters - a review, Environ. Technol., 15 (1994) 917-929.

[6] S. Meriç, H. Selçuk, V. Belgiorno, Acute toxicity removal in textile finishing wastewater by Fenton's oxidation, ozone and coagulation-flocculation processes, Water Res., 39 (2005) 11471153.

[7] H. Selçuk, G. Eremektar, S. Meriç, The effect of pre-ozone oxidation on acute toxicity and inert soluble COD fractions of a textile finishing industry wastewater, J. Hazard. Mater., 137 (2006) 254-260.
[8] T. Robinson, G. McMullan, R. Marchant, P. Nigam, Remediation of dyes in textile effluent: a critical review on current treatment technologies with a proposed alternative, Bioresour. Technol., 77 (2001) 247-255.

[9] P.C. Vandevivere, R. Bianchi, W. Verstraete, Review: Treatment and reuse of wastewater from the textile wet-processing industry: Review of emerging technologies, J. Chem. Technol. Biotechnol., 72 (1998) 289-302.

[10] R. Andreozzi, L. Campanella, B. Fraysse, J. Garric, A. Gonnella, R. Lo Giudice, R. Marotta, G. Pinto, A. Pollio, Effects of advanced oxidation processes (AOPs) on the toxicity of a mixture of pharmaceuticals, Water Sci. Technol., 50 (2004) 23.

[11] S. Ledakowicz, M. Solecka, R. Zylla, Biodegradation, decolourisation and detoxification of textile wastewater enhanced by advanced oxidation processes, J. Biotechnol., 89 (2001) 175-184.

[12] M. Pera-Titus, V. García-Molina, M.A. Baños, J. Giménez, S Esplugas, Degradation of chlorophenols by means of advanced oxidation processes: a general review, Appl. Catal., B, 47 (2004) 219-256.

[13] H. Selcuk, Decolorization and detoxification of textile wastewater by ozonation and coagulation processes, Dyes Pigm., 64 (2005) 217-222.

[14] B. Yuzer, M. Guida, F. Ciner, B. Aktan, M.I. Aydin, S. Meric, H. Selcuk, A multifaceted aggregation and toxicity assessment study of sol-gel-based $\mathrm{TiO}_{2}$ nanoparticles during textile wastewater treatment, Desal. Water Treat., 57 (2016) 4966-4973.

[15] H. Selcuk, J.J. Sene, M.A. Anderson, Photoelectro catalytic humic acid degradation kinetics and effect of $\mathrm{pH}$, applied potential and inorganic ions, J. Chem. Technol. Biotechnol., 78 (2003) 979-984.

[16] H. Selcuk, Decolorization of Textile Wastewater by Fenton Oxidation, in: Institute of Marine Sciences and Management, Istanbul University, 1997.

[17] A.Y. Zahrim, C. Tizaoui, N. Hilal, Coagulation with polymers for nanofiltration pre-treatment of highly concentrated dyes: A review, Desalination, 266 (2011) 1-16.

[18] A. Zahrim, C. Tizaoui, N. Hilal, Coagulation with polymers for nanofiltration pre-treatment of highly concentrated dyes: a review, Desalination, 266 (2011) 1-16.

[19] A.K. Verma, R.R. Dash, P. Bhunia, A review on chemical coagulation/flocculation technologies for removal of colour from textile wastewaters, J. Environ. Manage, 93 (2012) 154-168.

[20] Z.L. Yang, X.X. Liu, B.Y. Gao, S. Zhao, Y. Wang, Q.Y. Yue, Q. Li, Flocculation kinetics and floc characteristics of dye wastewater by polyferric chloride-poly-epichlorohydrin-dimethylamine composite flocculant, Sep. Purif. Technol., 118 (2013) 583-590.

[21] H.A. Arafat, Simple physical treatment for the reuse of wastewater from textile industry in the Middle East, J. Environ. Eng. Sci., 6 (2007) 115-122.

[22] K.P.Y. Shak, T.Y. Wu, Coagulation-flocculation treatment of high-strength agro-industrial wastewater using natural Cassia obtusifolia seed gum: Treatment efficiencies and flocs characterization, Chem. Eng. J., 256 (2014) 293-305.

[23] K. Paździor, J. Wrębiak, A. Klepacz-Smółka, M. Gmurek, L. Bilińska, L. Kos, J. Sójka-Ledakowicz, S. Ledakowicz, Influence of ozonation and biodegradation on toxicity of industrial textile wastewater, J. Environ. Manage., 195 (2017) 166-173.

[24] Q. Du, H. Wei, A.M. Li, H. Yang, Evaluation of the starch-based flocculants on flocculation of hair work wastewater, Sci. Total Environ., 601 (2017) 1628-1637.

[25] H. Selcuk, Ongen, Atakan, Aydin, M. Iberia, B. Yuzer, Industry Joint Project: Treatment of segregated textile process wastewater and reuse in the wet textile processes as salt liquor and process water, Final Report, in, Istanbul University, 2015.

[26] E.W. Rice, L. Bridgewater, A.P.H. Association, A.W.W. Association, W.E. Federation, Standard Methods for the Examination of Water and Wastewater, American Public Health Association, 2012.

[27] Turkish National Regulation of Water Pollution Control, in: Ministry of Environment and Forestry, 2004.

[28] A. Ongen, Y. Gunes, I. Talinli, Treatability of pesticide industry effluent by ozonation and coagulation. a real effluent investigation, J. Environ. Prot. Ecol., 13 (2012) 23-32. 
[29] M.I. Aydin, Assessment of biochemical methane potential of the concentrates that acquired from the treatment of textile wastewaters with membrane processes, in: Environmental Engineering, Yildiz Technical University, 2012.

[30] M. Butt, F. Arif, T. Shafique, N. Imtiaz, Spectro photo metric estimation of colour in textile dyeing wastewater, J. Chem. Soc. Pak., 27 (2005) 627-630.

[31] P. Asaithambi, A.R.A. Aziz, W.M.A.B.W. Daud, Integrated ozone-electro coagulation process for the removal of pollutant from industrial effluent: Optimization through response surface methodology, Chem. Eng. Process., 105 (2016) 92-102.

[32] Y. Yoon, Y. Hwang, M. Kwon, Y. Jung, T.-M. Hwang, J.-W. Kang, Application of $\mathrm{O}_{3}$ and $\mathrm{O}_{3} / \mathrm{H}_{2} \mathrm{O}_{2}$ as post-treatment processes for color removal in swine wastewater from a membrane filtration system, J. Ind. Eng. Chem., 20 (2014) 2801-2805.

[33] S. Lee, K. Lee, W.M. Wan, Y. Choi, Comparison of membrane permeability and a fouling mechanism by pre-ozonation followed by membrane filtration and residual ozone in membrane cells, Desalination, 178 (2005) 287-294.

[34] M. Sadrnourmohamadi, B. Gorczyca, Effects of ozone as stand-alone and coagulation-aid treatment on the reduction of trihalomethanes precursors from high DOC and hardness water, Water Res., 73 (2015) 171-180.

[35] K. Oh, P. Poh, M. Chong, D. Gouwanda, W. Lam, C. Chee, Optimizing the in-line ozone injection and delivery strategy in a multistage pilot-scale grey water treatment system: System validation and cost-benefit analysis, J. Environ. Chem. Eng., 3 (2015) 1146-1151.

[36] Y. Anjaneyulu, N.S. Chary, D.S.S. Raj, Decolourization of industrial effluents - available methods and emerging technologies - a review, Rev. Environ. Sci. Biotechnol., 4 (2005) 245-273.
[37] Z. Aksu, Application of biosorption for the removal of organic pollutants: a review, Process Biochem., 40 (2005) 997-1026.

[38] N. Hilal, O.O. Ogunbiyi, N.J. Miles, R. Nigmatullin, Methods employed for control of fouling in MF and UF membranes: a comprehensive review, Sep. Sci. Technol., 40 (2005) 19572005.

[39] W.-J. Lau, A.F. Ismail, Polymeric nanofiltration membranes for textile dye wastewater treatment: Preparation, performance evaluation, transport modelling, and fouling control - a review, Desalination, 245 (2009) 321-348.

[40] B. Van der Bruggen, G. Cornelis, C. Vandecasteele, I. Devreese, Fouling of nanofiltration and ultrafiltration membranes applied for wastewater regeneration in the textile industry, Desalination, 175 (2005) 111-119.

[41] N. Sapari, Treatment and reuse of textile wastewater by overland flow, Desalination, 106 (1996) 179-182.

[42] S. Gaydardzhiev, J. Karthikeyan, P. Ay, Colour removal from model solutions by coagulation-surface charge and floc characterisation aspects, Environ. Technol., 27 (2006) 193-199.

[43] B.-Y. Gao, Y. Wang, Q.-Y. Yue, J.-C. Wei, Q. Li, Color removal from simulated dye water and actual textile wastewater using a composite coagulant prepared by ployferric chloride and polydimethyldiallyl ammonium chloride, Sep. Purif. Technol., 54 (2007) 157-163.

[44] D. Georgiou, A. Aivazidis, J. Hatiras, K. Gimouhopoulos, Treatment of cotton textile wastewater using lime and ferrous sulfate, Water Res., 37 (2003) 2248-2250.

[45] A. Akbari, J.C. Remigy, P. Aptel, Treatment of textile dye effluent using a polyamide-based nano filtration membrane, Chem. Eng. Process., 41 (2002) 601-609. 